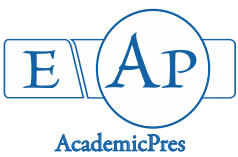

Mondal PC et al. (2021)

Notulae Scientia Biologicae

Volume 13, Issue 3, Article number 10992

DOI: $10.15835 / \mathrm{nsb} 13310992$

Research Article

\title{
Vulvo-vaginal myiasis among rural women in West Bengal, India
}

\section{Prabhat C. MONDAL ${ }^{1}$, Santanu MAHATO ${ }^{2}$, Dinabandhu SAHIS ${ }^{1}$, Barunodoy CHAKRABORTY', Rajendra P. MONDAL ${ }^{3}$, Pravas HAZARI ${ }^{4}$, Shuvra K. SINHA ${ }^{4 *}$}

\author{
${ }^{1}$ Bankura Sammilani Medical College, Bankura 722102, West Bengal, India; prabhatmndl@yahoo.co.in; \\ asmp80@rediffmail.com; drsahis@gmail.com \\ ${ }^{2}$ University of Mysore, Biopsychology Laboratory and Institution of Excellence, Mysuru 570006, Karnataka, \\ India; santanumahato94@gmail.com \\ ${ }^{3}$ Bankura Sammilani College, Department of Zoology, Bankura 722101, West Bengal, India; rpmondal09@gmail.com \\ ${ }^{4}$ Sreegopal Banerjee College, Calyptrate Research Laboratory, Department of Zoology, Hooghly 712148, West Bengal, India; \\ pravashazari2017@gmail.com;suvrosinha@gmail.com (*correspondingauthor)
}

\begin{abstract}
Myiasis, the infestation of living or dead tissue of vertebrates by larvae (maggots) of dipterous flies, is well-known in the medical field. Different parts of the human body, such as skin, oral, nasal, urogenital are affected and named accordingly. The present study was a clinic-entomological study where the women having vulvo-vaginal myiasis were included. Maggots were collected, cultured, and adult flies were identified. A total of 34 cases of vulvo-vaginal myiasis were treated. The larvae of 29 cases were cultured into adults. Most of the women are rural (94\%), illiterate and from a low socioeconomic society. The authors specified the infested sites of vulva and vagina such as vaginal, labia, clitoris, episiotomy wound, vulval growth, and prolapsed uterus. The episiotomy wound $(32 \%)$ is the most common infestation site, followed by the vagina (26\%). Chrysomya bezziana (76\%) and Chrysomya megacephala (24\%) are the identified flies. Illiterate, rural puerperal mothers of low socioeconomic status without proper health education and basic hygiene knowledge are vulnerable to myiasis.
\end{abstract}

Keywords: Chrysomya bezziana; Chrysomya megacephala; myiasis; poor hygiene; rural areas

\section{Introduction}

Myiasis is a zoonotic disease in which larvae (maggots) of the dipterous fly infest humans and vertebrates' dead or healthy tissue (Smith, 1986; Robbins and Khachemoune, 2010). Different parts of the human body, such as skin, oral, nasal, urogenital are affected and named accordingly. The most prevalent site of infestation is the skin (Caumes et al., 1995), while the genitourinary region is the least common (Francesconi and Lupi, 2012). Human myiasis is of great veterinary importance but most health care professionals often consider myiasis as a minor clinical entity and report intermittently, limiting clinical details and patient characteristics in the academic field (Robbins and Khachemoune, 2010). It is relatively less studied and the data up to species level identification is often unavailable on human myiasis. Although maggot culture is frequently used in the

Received: 12 Jun 2021. Received in revised form: 09 Aug 2021. Accepted: 11 Aug 2021. Published online: 18 Aug 2021. From Volume 13, Issue 1, 2021, Notulae Scientia Biologicae journal uses article numbers in place of the traditional method of continuous pagination through the volume. The journal will continue to appear quarterly, as before, with four annual numbers. 
treatment of patients, species identification is not part of medical therapy (Fonseca-Muoz et al., 2020). Identification of maggots is helpful in determining the timing of infestation, clinical outcome, and place of infestation (Sherman, 2000). Species identification requiring adult fly is to estimate the timing and circumstances of maggot infestation more specifically, as some species have a characteristic life cycle different from others of the same family, addiction to host and type of tissue, living or dead (Sherman, 2000; Beyramysoltan et al., 2020). Moreover, Vulvar myiasis is a rare disease that accounts for only $0.7 \%$ of human infestations (Sherman, 2000). In Ecuador, it varies from 4.7 to 23/100,000 population according to the region (Calvopina et al., 2020). A number of unusual cases of vaginal myiasis have been reported around the world: USA (Bury et al., 1979); Hong Kong (Chan et al., 2005); Japan (Chigusa et al., 2005); Brazil (Garbeloto et al., 2013); UK (Soulsby et al., 2016); and India (Gupta et al., 2014; Mondal et al., 2016; Paul et al., 2021). The current study was a clinico-entomological investigation into vulvo-vaginal myiasis in the Bankura district of West Bengal, India, where it has the potential to become the most frequent personal hygiene-associated skin disease, with more species and greater abundance in lower socioeconomic regions.

\section{Materials and Methods}

Several cases of vaginal myiasis were reported from different parts of the Bankura District, West Bengal, India. Three rural hospitals in Bankura district were requested to take part in the study. Female patients with vulvo-vaginal myiasis were included in the present study between January, 2017 and December, 2019. Each woman was placed in a lithotomy position and vulvo-vaginal regions were examined by the respective gynecologist. Vagina, labia and clitoris were thoroughly searched for maggots and burrows. Visible maggots were grasped carefully by forceps and hidden maggots were collected during subsequent dressings. Ether, routinely used to kill maggots in many hospitals, was not used during the present study to collect live maggots. Collected maggots were kept in properly labeled bottles filled with fresh raw chicken meat pieces for transportation. Wounds were cleaned with a saline-antibiotic solution and maggots were removed during subsequent dressing if detected. Oral antibiotics and analgesics were prescribed.

After the collection of maggots from every patient, the consent form, labeled bottle and the examination sheet containing details of the patient and clinical findings were sent to the entomology laboratory of Sonamukhi College, where maggots were photographed. Again, fresh raw chicken meat was used as a culture medium for the maggots. After attaining the third instar stage on rearing material, the matured and sluggish maggots were transferred to another culture jar containing moist saw dust, where the maggots transformed into pupae. After six days (Average temp. $34^{\circ} \mathrm{C}$ and $\mathrm{RH} 72 \%$ ) of pupation, adult flies were emerged out. The authors (SM, PH, and SKS) identified the emerged adult flies up to species level by studying morphological characteristics following Senior-White et al. (1940) and Smith (1986).

\section{Results}

Over the three-year period, a total of 34 patients fulfilled the selection criteria. Most of them are poor (91\%), illiterate (79\%), and rural women (94\%) of Bankura district (Table 1). Maggots from all cases had been collected and brought to the entomological laboratory, where successful rearing was possible in 29 (85\%) cases. Maggots of five cases (15\%) died during the rearing process, which could be due to use of certain chemicals on the patients before admission to the hospital. Most of the women (76\%) were affected between the ages of 26 and 49 years, whereas only six women (18\%) were between 15 and 25 years. Two women above 50 years were also affected (Table 1). 
Table 1. Sociodemographic features of affected women

\begin{tabular}{|c|c|}
\hline Characteristics $(n=34)$ & Number (\%) \\
\hline \multicolumn{2}{|l|}{ Place of residence } \\
\hline Rural & $32(94)$ \\
\hline Urban & $2(6)$ \\
\hline \multicolumn{2}{|l|}{ Age, years } \\
\hline $15-25$ & $6(18)$ \\
\hline $26-49$ & $26(76)$ \\
\hline $50-60$ & $2(6)$ \\
\hline \multicolumn{2}{|l|}{ Socioeconomic status } \\
\hline Low & $31(91)$ \\
\hline Medium & $2(6)$ \\
\hline High & $1(3)$ \\
\hline \multicolumn{2}{|l|}{ Literacy } \\
\hline Literate & $7(21)$ \\
\hline Illiterate & $27(79)$ \\
\hline
\end{tabular}

During puerperium, 11 (32\%) lactating mothers suffered the infestation at the episiotomy wound. Infestation of maggots was seen in nine cases in the vagina (26\%), five cases in labia minora and clitoris (15\%), four cases in labia majora (12\%), and only three cases in labia minora (9\%) (Table 2). Infestation of women above 60 years was in the prolapsed vagina and vulval growth (Figure 1). The vulval growth was later diagnosed as squamous cell carcinoma.

Table 2. Sites of infestation in vulvo-vaginal region

\begin{tabular}{|l|c|}
\hline \multicolumn{1}{|c|}{ Site infested $(\mathrm{n}=34)$} & Number (\%) \\
\hline Vaginal mucosa & $9(26)$ \\
\hline Labia majora & $4(12)$ \\
\hline Labia minora & $3(9)$ \\
\hline Labia minora and clitoris & $5(15)$ \\
\hline Episiotomy wound & $11(32)$ \\
\hline Vulval growth & $1(3)$ \\
\hline Prolapsed uterus & $1(3)$ \\
\hline
\end{tabular}

Among the 29 flies grown in the laboratory, 22 were Old World Screwworm Chrysomya bezziana, and seven were Latrine fly Chrysomya megacephala (Table 3, Figure 2). Five larva was dead, and could not be grown, was from Chrysomya bezziana. Interestingly, Chrysomya megacephala affected all age groups in the study, but Chrysomya megacephala affected mainly puerperal cases in the infected episiotomy wounds.

Table 3. Species causing myiasis

\begin{tabular}{|l|c|}
\hline \multicolumn{2}{|c|}{ Species identified by culture $(\mathrm{n}=29)$} \\
\hline Name of species & Number (\%) \\
\hline Chrysomya bezziana & $22(76)$ \\
\hline Chrysomya megacephala & $7(24)$ \\
\hline \multicolumn{2}{|c|}{ Species identified from maggots $(\mathrm{n}=5)$} \\
\hline Chrysomya bezziana & 5 \\
\hline
\end{tabular}


Mondal PC et al. (2021). Not Sci Biol 13(3):10992
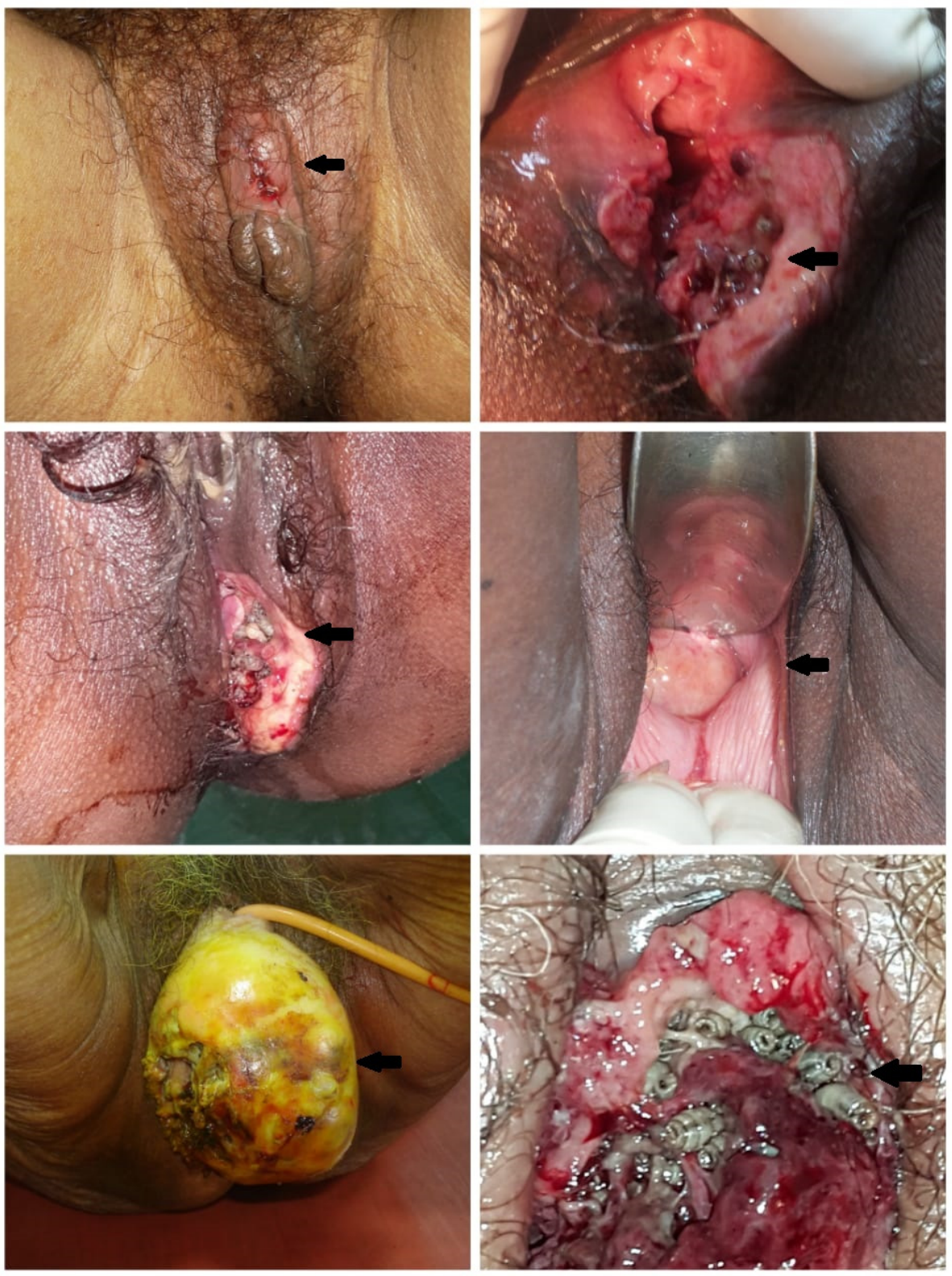

Figure 1. An illustration of infested vaginas during the case studies 

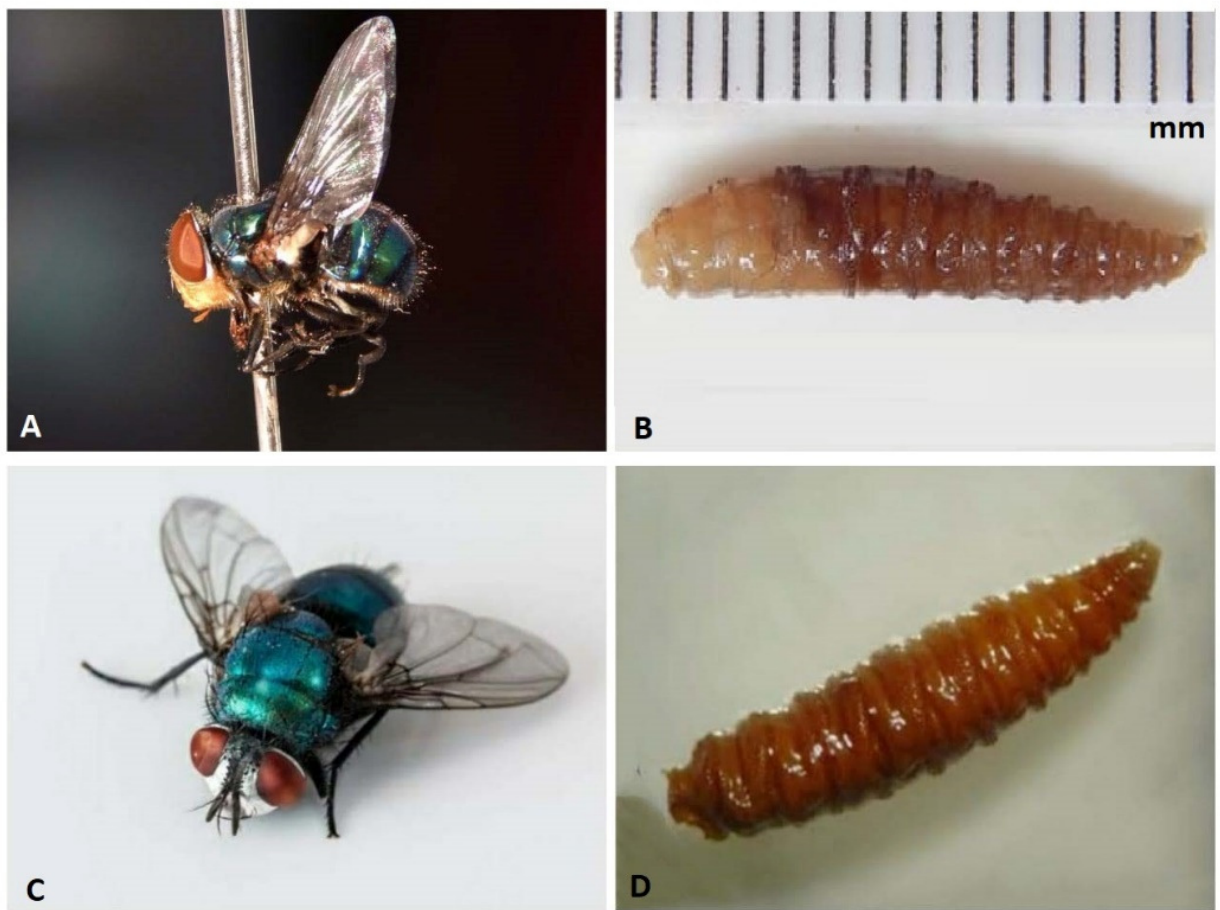

Figure 2. (A) Latrine fly Chrysomya megacephala, (B) Third instar larva of C. megacephala extracted from vagina, (C) Old world screwworm Chrysomya bezziana, (D) Third instar larva of $C$. bezziana extracted from vagina

\section{Discussion}

A total of 34 women were from rural areas between 15 and 50 years of age and from low socioeconomic status, having poor hygiene and low literacy levels (Table 1). However, no age group is immune to infestation (Ziaei Hezarjaribi et al., 2014). Myiasis of exposed wounds can be explained by direct deposition of eggs by adult flies as flies are attracted by the smell of blood (Kataria et al., 2013) but the covered vulval region is affected rarely. The mode of egg deposition is really surprising. Women from rural areas of Bankura district usually do not use undergarments and sanitary napkins during menstruation. They use clothes like handkerchief-size and shape to cover the vulva antero-posteriorly as a menstrual blood absorbent. The clothes are washed and dried in the open air for reuse. Blood mixed clothes attract flies for egg deposition (Kataria et al., 2013).

Episiotomy wound was the single most common site of infection (32\%) in the present study (Table 2). The creeping sensation, visible maggots and disruption of wounds are psychologically traumatic for young mothers during their glorious moments of life. Rural women are ignorant of episiotomy wound care after discharge from the hospital. Infected wounds soaked with fowl smelling lochia may attract flies for deposition of eggs while defecating in the field. Egg deposition could have been through the clothes used for covering the vulva or directly during sitting open. Dohiya and Khosla (2002) reported three cases of vulval myiasis due to home delivery by traditional birth attendants (Dahiya and Khosla, 2002). However, in the present study, all mothers (11 of 34 cases) were delivered at hospitals and discharged after 48 hours. Inoculation might be at home due to poor hygiene and lack of health consciousness.

Vulval myiasis is so rare that its classification has not been documented depending upon the structures involved such as vagina, labia, clitoris, or any wound (ulcers, cancerous growth). Among the cases, labia (majus and minus) with clitoris are the predominant site of infestation (36\%), followed by episiotomy wounds (32\%) (Table 2). Maggots were recovered from the vaginal canal of nine women (26\%). Accompanied by burrowing 
lesions, these cases are called vaginal myiasis (Figure 1). Long-standing untreated huge utero-vaginal prolapse often results in decubitus or venous ulcers. Elderly village women are bound to support the prolapse by binding the vulva antero-posteriorly with clothes. The study reports myiasis in a vulval growth which was later diagnosed as vulval carcinoma.

No deaths were reported during the study period. All the women were relieved with dressing. However, surgical intervention was required for resuturing episiotomy wounds in all cases for the restoration of vulval anatomy and coital function. Radical vulvectomy was done in one case of vulval cancer. The women having long-standing genital prolapse got the definitive care, vaginal hysterectomy with apical suspension and pelvic floor reconstruction following healing of ulcer. Saldarriaga et al. (2011) reported a similar case of myiasis in genital prolapse due to personal neglect and poor hygiene. Ivermectin was used in the case. Only four cases have been reported in the literature.

Among the 16 families of insects belonging to the Diptera order, only 5 are important in medical entomology: Muscidae, Sarcophagidae (flesh flies), Calliphoridae (blow flies), Oestridae (bot flies), and Cuterebridae. Old world screwworm Chrysomya bezziana and Oriental latrine fly Chrysomya megacephala were two identified species in the study (Figure 2), abundant in rural India and mostly facultative parasites which usually infest decaying organic matter like the dead bodies of different animals. C. bezziana is a common myiasis causing fly and is an obligatory parasite of mammals, including humans (Mondal et al., 2016). Mondal et al. (2016) reported C. megacephala causing vaginal myiasis for the first time in the Bankura district of West Bengal, India and also highlighted the importance of maintaining personal hygiene to avoid larval infestations.

\section{Conclusions}

The incidence of vulvo-vaginal myiasis is likely to be underestimated as it is occasionally documented in case reports. Even though this type of report is documented in the health center, most women refuse infectious tissue and maggots to be collected for further examination. They usually avoid talking about the issue with researchers. Rural, poor, illiterate women having limited experience of maintaining genital hygiene are the most vulnerable group. Health education about episiotomy wound care and the supply of sanitary napkins during discharge of lactating mothers following vaginal deliveries could be of paramount help in reducing episiotomy wound myiasis. Furthermore, more focus must be given to sharing the knowledge gained from this type of cases to illiterate and tribal women in order to maintain good personal hygiene.

\section{Authors' Contributions}

Conceptualization: PCM, SM and SKS; Data curation and Investigation: PCM, BC, and DS; Methodology: SM, RPM, PH and SKS, Supervision: PCM and SKS; Validation: PCM, BC, and DS; Visualization: PCM, SM, RPM and SKS, Writing - original draft: PCM, SM and SKS; Writing - review and editing: SM, RPM and PH. All authors read and approved the final manuscript.

\section{Ethical approval}

The study was approved by the Research Ethics Committee of Bankura Sammilani Medical College, Bankura, West Bengal, India. Written consent for participation in the present study and the culture of maggots was taken from the patients. 


\section{Acknowledgements}

The authors are thankful to the authorities of the Bankura Sammilani Medical College and Hospital for the necessary permission, and to the principals of Sonamukhi College and Sreegopal Banerjee College for providing laboratory facilities to culture the maggots.

\section{Conflict of Interests}

The authors declare that there are no conflicts of interest related to this article.

\section{References}

Beyramysoltan S, Ventura MI, Rosati JY, Giffen-Lemieux JE, Musah RA (2020). Identification of the species constituents of maggot populations feeding on decomposing remains-facilitation of the determination of post mortem interval and time since tissue infestation through application of machine learning and direct analysis in real timemass spectrometry. Analytical Chemistry 92:5439-5446. https://doi.org/10.1021/acs.analchem.0c00199

Bury TL, Clegern RW, Hart WW (1979). Two cases of phorid (Diptera: Phoridae) myiasis in Texas. Journal of Medical Entomology 15:122-3.

Calvopina M, Ortiz-Prado E, Castañeda B, Cueva I, Rodriguez-Hidalgo R, Cooper PJ (2020). Human myiasis in Ecuador. PLoS Neglected Tropical Diseases 14:e0007858. https://doi.org/10.1371/journal.pntd.0007858

Caumes E, Carrière J, Guermonprez G, Bricaire F, Danis M, Gentilini M (1995). Dermatoses associated with travel to tropical countries: a prospective study of the diagnosis and management of 269 patients presenting to a tropical disease unit. Clinical Infectious Diseases 20:542-8. https://doiorg/10.1093/clinids/20.3.542

Chan JC, Lee JS, Dai DL, Woo J (2005). Unusual cases of human myiasis due to Old World screwworm fly acquired indoors in Hong Kong. Transactions of the Royal Society of Tropical Medicine and Hygiene 99:914-8. https://doi.org/10.1016/j.trstmh.2005.06.020

Chigusa Y, Shinonaga S, Honda M, Kanma W, Kakinuma H, Kirinoki M, Matsuda H (2005). Vaginal myiasis due to Sarcophaga peregrina (Diptera: Sarcophagidae) on a patient with atrial fibrillation, cerebral infarction and leg amputation. Medical Entomology and Zoology 56:247-9. https://doi.org/10.7601/mez.56.247

Dohiya K, Khosla AH (2002). Vulvo-vaginal infestation with maggots. International Journal of Gynecology and Obstetrics 79:55-56. https://doi.org/10.1016/s0020-7292(02)00142-x

Francesconi F, Lupi O (2012). Myiasis. Clinical Microbiology Reviews 25:79-105. https://doi.org/10.1128/CMR.00010-11

Fonseca-Muñoz A, Sarmiento-Jiménez HE, Pérez-Pacheco R, Thyssen PJ, Sherman RA (2020). Clinical study of maggot therapy for Fournier's gangrene. International Wound Journal 17:1642-9. https://doi.org/10.1111/iwj.13444

Garbeloto E, de Souza-Trindade B, Alves-Canal F, Chambô-Filho A (2013). Genital and breast myiasis: case series. The Journal of Tropical Medicine and Parasitology 36:98-104.

Gupta R, Singh I, Sharma SB, Patel J (2014). White discharge per vaginum: can it be vaginal myiasis? Indian Obstetrics and Gynaecology 4:30-32.

Kataria U, Siwach S, Gupta S (2013). Myiasis in female external genitalia. Indian Journal of Sexually Transmitted Diseases and AIDS 34:129-131. https://doi.org/10.4103/0253-7184.120555

Mondal PC, Mahato S, Chakraborty B, Sinha SK (2016). First report of Oriental latrine flies causing vaginal myiasis in human. Journal of Parasitic Diseases 40:1243-1245. https://doi.org/10.1007/s12639-015-0660-6

Robbins K, Khachemoune A (2010). Cutaneous myiasis: a review of the common types of myiasis. International Journal of Dermatology 2010 49:1092-1098. https://doi.org/10.1111/j.1365-4632.2010.04577.x

Paul S, Upreti P, Makhija A, Nautiyal R (2021). Urogenital myiasis-An atypical presentation. Autopsy and Case Reports 11:e2020192. https://doi.org/10.4322/acr.2020.192

Saldarriaga W, Herrera E, Castro D (2011). Myasis in uterine prolapse, successful treatment. American Journal of Obstetrics and Gynecology 205:e5-6. https://doi.org/10.1016/jajog.2011.03.019 
Senior-White R, Aubertin D, Smart J (1940). Fauna of British India, including the remainder of the Oriental Region: Diptera. Family Calliphoridae. Taylor and Francis, London.

Sherman RA (2000). Wound myiasis in urban and suburban United States. International Archives of Internal Medicine 160:2004-2014. https://doi.org/10.1001/archinte.160.13.2004

Smith KGV (1986). A manual of forensic entomology. Trustees of the British Museum. Natural History and Cornell University Press, London.

Soulsby H, Jones BL, Coyne M, Alexander CL (2016). An unusual case of vaginal myiasis. JMM Case Reports 3:e005060. https://doi.org/10.1099/jmmcr.0.005060

Ziaei Hezarjaribi H, Taghavi M, Fakhar M, Seyrafi A, Enayati AA (2014). Vaginal myiasis due to Fannia scalaris. International Journal of Gynecology and Obstetrics 127:300. https://doi.org/10.1016/j.ijgo.2014.07.017
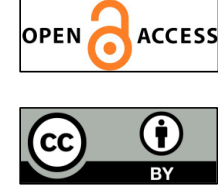

The journal offers free, immediate, and unrestricted access to peer-reviewed research and scholarly work. Users are allowed to read, download, copy, distribute, print, search, or link to the full texts of the articles, or use them for any other lawful purpose, without asking prior permission from the publisher or the author.

License - Articles published in Notulae Scientia Biologicae are Open-Access, distributed under the terms and conditions of the Creative Commons Attribution (CC BY 4.0) License.

(c) Articles by the authors; SHST, Cluj-Napoca, Romania. The journal allows the author(s) to hold the copyright/to retain publishing rights without restriction. 